\title{
AVALIAÇÃO DA EFICIÊNCIA DE BARREIRA REATIVA INSTALADA EM ESCALA PILOTO PARA DEGRADAÇÃO ABIÓTICA DE SOLVENTES ORGANOCLORADOS
}

\author{
Flávio Augusto Ferlini Salles e Uriel Duarte
}

\begin{abstract}
RESUMO Em abril de 1999 foi instalada barreira reativa (sistema funnel and gate) para degradação abiótica de solventes clorados presentes em água subterrânea a jusante da Solventex Indústria Química Ltda, localizada em São Paulo SP, Brasil. O sistema instalado em escala piloto foi monitorado ao longo de 29 meses para acompanhamento das concentrações dos contaminantes de interesse antes e após a passagem pelo sistema de remediação. Os resultados dos últimos 12 eventos de monitoramento (outubro de 2000 a setembro de 2001) comprovaram a eficiência esperada do sistema para degradação dos solventes clorados com dupla ligação (etenos) e ainda apresentaram resultados positivos na degradação de etanos. As concentrações medidas em três poços de monitoramento, instalados a montante, jusante e dentro da barreira reativa forneceram evidências do processo de degradação a partir das quais puderam ser observadas a total dehalogeneização dos etenos. A barreira instalada com profundidade de 5,15 m, comprimento de 3,0 m e largura de 1,20 m foi preenchida por mistura de granalha de aço e areia na proporção em massa de 81,9\% de areia para 18,1\% de granalha, quantidade de ferro pouco superior ao valor encontrado na literatura e que culminou na eficiência esperada do sistema mesmo após 2 anos e 5 meses de funcionamento contínuo sem alterações.
\end{abstract}

Palavras-Chaves: Remediação; Solventes Clorados; Barreiras Reativas

\begin{abstract}
A reactive barrier (funnel and gate system) was installed in April 1999 for abiotic degradation of chlorinated solvents present in groundwater, downgradient of the Solventex Indústria Química Ltda. The system was installed on pilot scale and monitored for 29 months for evaluate the contaminants concentrations before and after the treatment on the reactive barrier. The results of the last 12 monitoring events (October 2000 to September 2001) confirmed the expected efficiency of the system on degradation of ethenes and showed unexpected positive results on degradation of ethanes. Measured concentrations on three monitoring wells, upgradient, downgradient and inside the reactive barrier, provided evidences of the degradation processes with total ethenes dehalogenation. The reactive barrier was $5.15 \mathrm{~m}$ depth, $3.0 \mathrm{~m}$ length and $1.20 \mathrm{~m}$ width and was filled with sand and zero valent iron on the mass proportion of $81.9 \%$ of sand and $18.1 \%$ of iron, mass of iron high to the value founded on bibliography, but efficient even after 2 ages and 5 months of operation without modifications.
\end{abstract}

Keywords: reactive barrier, remediation, contaminants, dehalogenation

\section{INTRODUÇÃO}

A Companhia de Tecnologia de Saneamento Ambiental (CETESB) divulgou em outubro de 2003 uma lista de áreas contaminadas catalogadas no Estado de São Paulo. Das 727 áreas listadas pela CETESB, 57 apresentam a citação geral de compostos “clorados" ou "halogenados" (caso da Solventex) como contaminantes de interesse. Outras áreas listadas apresentam compostos da mesma natureza, contudo especificados (tricloreteno, por exemplo). No entanto, em todo o documento elaborado pela CETESB (2003), em apenas 3 casos é identificada a aplicação de barreira reativa como processo de "remediação adotado", e ainda assim apenas duas aplicadas para áreas contaminadas por compostos clorados.
A Solventex Indústria Química Ltda,

localizada no bairro de Parelheiros, em São Paulo - SP, é um destes dois casos de aplicação de barreira reativa citados no documento CETESB (2003), sistema que foi instalado em abril de 1999 para tratamento in situ da água subterrânea contaminada por solventes clorados.

Entre os meses de maio de 1999 e setembro de 2001 o sistema de remediação foi monitorado através de poços de monitoramento localizados a montante, jusante e interior da barreira, com coletas de amostras de água subterrânea e análises químicas mensais para avaliação evolutiva da contaminação.

Este trabalho visa apresentar os resultados deste monitoramento e a avaliação dos resultados obtidos com o método de remediação pioneiro no Brasil.

\footnotetext{
${ }^{1}$ Instituto de Geociências, Universidade de São Paulo (flavio.salles@estre.com.br), (urduarte@usp.br)
} 


\section{APLICAÇÃO DEGRADAÇÃO CLORADOS \\ DE FERRO PARA DE SOLVENTES}

Segundo GILLHAM; O’HANNESIN (1992), metais favorecem significativamente a degradação de compostos halogenados alifáticos. A razão de degradação destes compostos na presença de metais acresce em cerca de três a seis vezes a razão natural reportada por VOGEL et al. (1987) em GILLHAM; O’HANNESIN (1992).

O mecanismo de degradação aparenta ser predominantemente abiótico e exige a presença de condições altamente redutoras e de superfícies metálicas, as quais devem agir como doadoras de elétrons.

Barreiras sub-superficiais contendo metais em mistura com solo de granulometria adequada ao aqüífero estudado permitem o tratamento completo da pluma de contaminação através de método totalmente passivo. $\mathrm{O}$ desenho da barreira, em especial a sua espessura, dependerá da meia-vida de cada contaminante a ser tratado, da concentração inicial deste, da concentração alvo a ser alcançada após a passagem pela barreira e do fluxo da água subterrânea no local.

Para os compostos organoclorados (exceto 1,2 Dicloroetano) analisados na Solventex, GILLHAM; O’HANNESIN (1992) apresentam os tempos requeridos à redução em $50 \%$ na concentração após fluxo através de barreira reativa constituída por diversos reagentes metálicos (Tabela 1).

Tabela 1 - Tempo, em minutos, para redução da concentração em 50\%

\begin{tabular}{c|c|c|c|c|c}
\hline Metal & Clorofórmio & $\begin{array}{c}1,1,1 \\
\text { Tricloroetano }\end{array}$ & $\begin{array}{c}\text { Tetracloreto } \\
\text { de } \\
\text { Carbonato }\end{array}$ & Tricloroetileno & Tetracloroetileno \\
\hline Aço Inoxidável & & $>40000$ & & $>40000$ & $>40000$ \\
\hline Cobre & & $>40000$ & & $>40000$ & $>40000$ \\
\hline Bronze & & $>40000$ & & $>40000$ & $>40000$ \\
\hline Alumínio & & 9000 & & 40000 & 30000 \\
\hline Aço Doce & 6000 & 180 & 200 & 5000 & 10000 \\
\hline Metal Galvanizado & 1200 & 200 & 180 & $>40000$ & 5000 \\
\hline
\end{tabular}

De uma maneira geral, os tempos obtidos através da utilização de metal galvanizado foram menores do que os valores obtidos na utilização de outros metais. Apenas o tempo para degradação do Tricloroetileno (TCE) é evidentemente menor na utilização do Aço Doce.

ORTH; GILLHAM (1993) concluíram que na presença de pó de ferro eletrolítico é rápida a degradação do TCE, com tempo de degradação estimado em $3,25 \mathrm{~h}$ para a meia-vida deste contaminante. Após a normalização da coluna utilizada no experimento ao tempo de residência, foram observadas razões semelhantes de degradação para concentrações no intervalo de 1,27 a $61,0 \mathrm{mg} / \mathrm{L}$ de TCE.

\section{INSTALAÇÃO DA BARREIRA REATIVA}

A área foi avaliada através da instalação de 26 poços multiníveis (14 com três níveis distintos de investigação e 12 com dois níveis) de monitoramento (PMs) do aqüífero freático, tendo sido determinado o fluxo preferenci al da água subterrânea com sentido norte-sul.

O eixo central da pluma de contaminação constituída basicamente por compostos organoclorados e por hidrocarbonetos derivados de petróleo foi determinado a jusante da área da indústria, configurando área potencialmente favorável à instalação da Barreira Reativa, conforme indicada na figura 1 .

A descrição dos perfis de sondagens efetuadas no local indicou o topo da camada rochosa que constitui o embasamento local em profundidade aproximada de $6,0 \mathrm{~m}$, suficiente para sua interceptação com retro-escavadeira tradicional.

A origem da contaminação e as atividades da indústria (fabricação de solventes a partir de matérias primas diversas, como borra de tintas) não permitem definir a composição da pluma inicial de contaminantes, desta forma inviabilizando o balanço de massa para avaliar a eficiência de métodos de remediação.

Empregou-se para instalação da barreira reativa uma retro-escavadeira modelo PC 150 (Figura 2). 


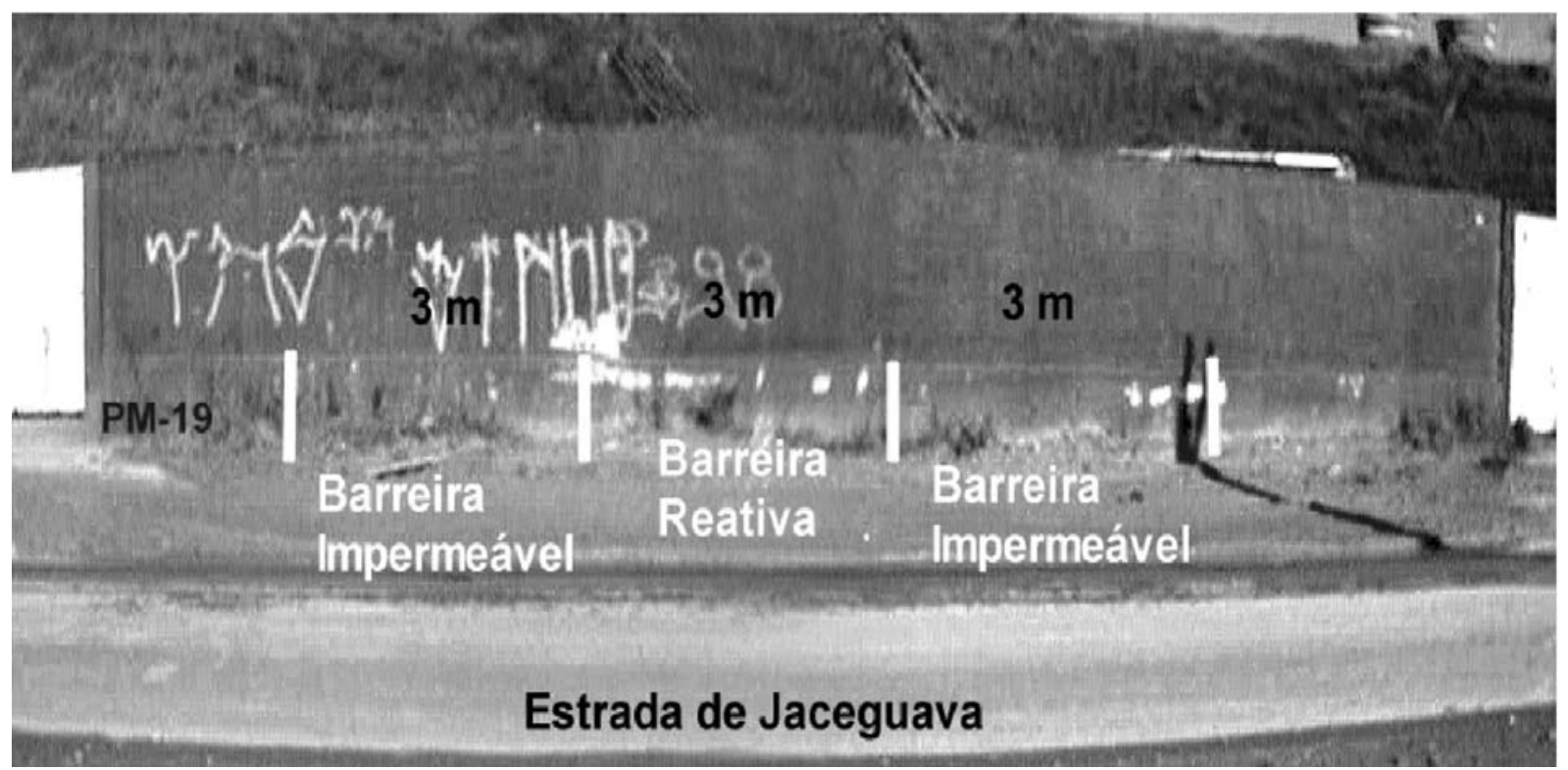

Figura 1 - Distribuição aproximada do sistema instalado

A descrição dos perfis de sondagens efetuadas no local indicou o topo da camada rochosa que constitui o embasamento local em profundidade aproximada de $6,0 \mathrm{~m}$, suficiente para sua interceptação com retro-escavadeira tradicional.

A origem da contaminação e as atividades da indústria (fabricação de solventes a partir de matérias primas diversas, como borra de tintas) não permitem definir a composição da pluma inicial de contaminantes, desta forma inviabilizando o balanço de massa para avaliar a eficiência de métodos de remediação. Empregouse para instalação da barreira tiva uma retro-escavadeira modelo PC 150 (Figura 2).

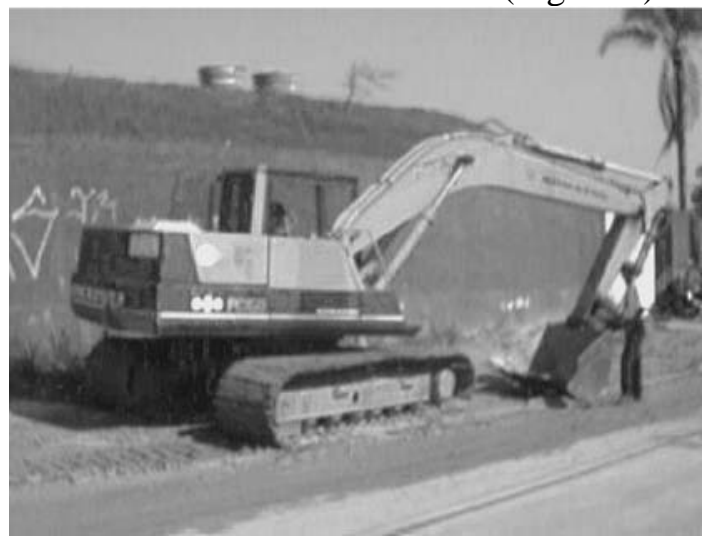

Figura 2 -Escavadeira modelo PC-150

A trincheira foi construída com extensão de $3,0 \mathrm{~m}$ e sua largura foi pré-definida em $0,99 \mathrm{~m}$ a partir das concentrações dos compostos clorados obtidas nas etapas de avaliação da contaminação e a partir dos valores de meia-vida estabelecidos em GILHAM; O’HANNESIN (1992), sendo a largura mínima calculada para completa dehalogeneização dos contaminantes de interesse. Entretanto, em virtude do colapso de solo durante o processo de escavação, provocado pela raspagem da pá-cavadeira de largura de $1,20 \mathrm{~m}$, a trincheira foi escavada com largura aproximada de $1,50 \mathrm{~m}$.

A escavação (Figura 3) não necessitou de escoramento, uma vez que a profundidade de $5,15 \mathrm{~m}$ foi atingida passando-se por solo de alteração (grau elevado) de rocha com matriz argilosa, compacto e estável, não tendo sido observada a migração de água subterrânea para a cava durante o processo.

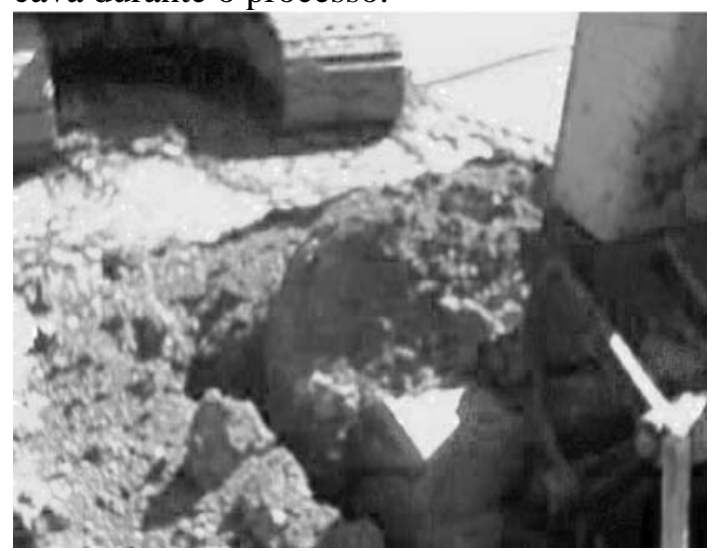

Figura 3 - Escavação para barreira reativa

Durante a escavação da trincheira para inserção do material reativo e de duas trincheiras adjacentes a esta, destinadas à instalação das placas metálicas (barreira impermeável para direcionamento do fluxo da água subterrânea sistema funnel and gate), não foi observada a 
migração imediata de água na profundidade estimada de interceptação do aqüífero freático. A migração lenta de água foi identificada após horas de trabalhos, durante a cravação das placas metálicas, evidenciando a baixa condutividade hidráulica do meio avaliado.

$\mathrm{Na}$ profundidade de 5,15 m atingida pela escavação foi encontrada a transição para solo medianamente alterado, com a presença de rocha alterada dura e de matacões de rocha (Figura 4), profundidade na qual procedeu-se a inserção das placas metálicas sob controle de nivelamento, obtendo-se posição vertical da estrutura.

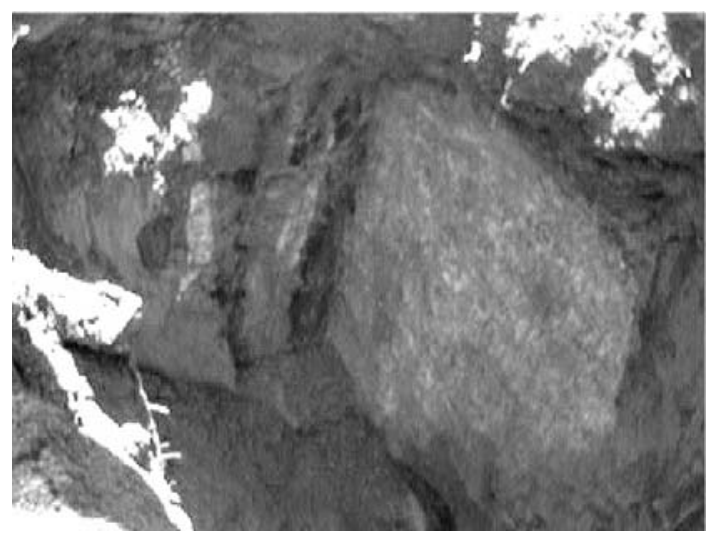

Figura 4 - Fragmento de rocha alterada encontrado na escavação da porção leste da trincheira

As cavas e placas foram feitas individualmente, sendo iniciada pela colocação da placa leste, sob ângulo aproximado de $\mathrm{N} 85^{\circ}$. Após inserção da placa foi realizada cravação através de pressão vertical efetuada com o auxílio da pá da retro-escavadeira, processo atuante até posicionamento final da placa no nível do pavimento (Figura 5).

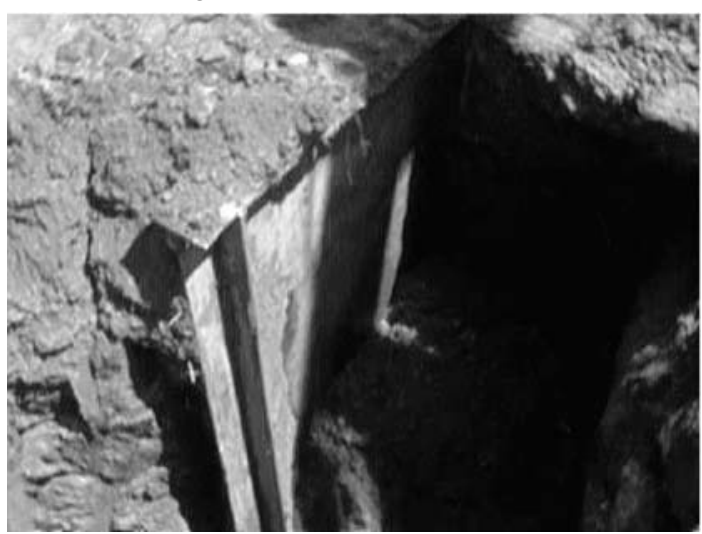

Figura 5 - Posicionamento vertical da placa leste após cravação

Finalizado o processo de inserção e cravação das placas, procedeu-se o preenchimento da cava por reposição do solo escavado. As placas, desta forma, foram mantidas sob o solo, conforme apresentado na figura 6, reduzindo os efeitos de abrasão por atritos superficiais.

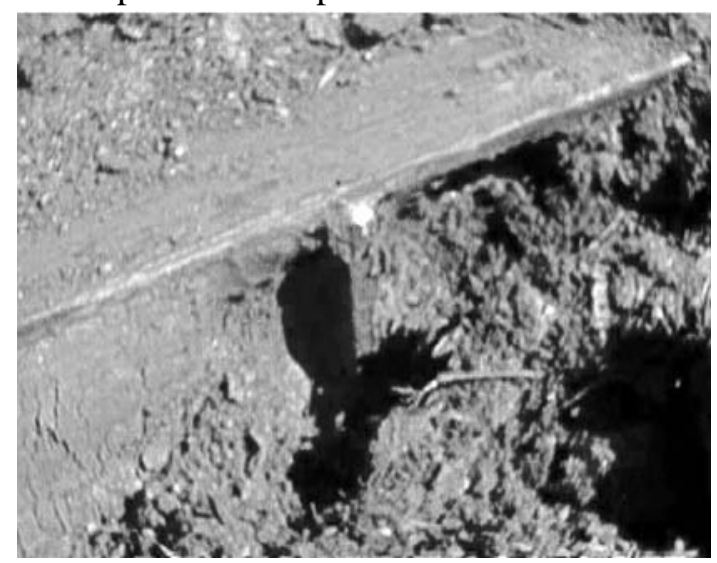

Figura 6 - Detalhe da placa da barreira impermeável oeste, cravada sob a superfície do solo

Previamente ao preenchimento da trincheira pelo material reativo, foi inserida placa guia em madeira (Figura 7), posicionada verticalmente, de forma a limitar a área de preenchimento. A largura final da Barreira Reativa, com a inserção da placa guia, ficou em 1,20 m.

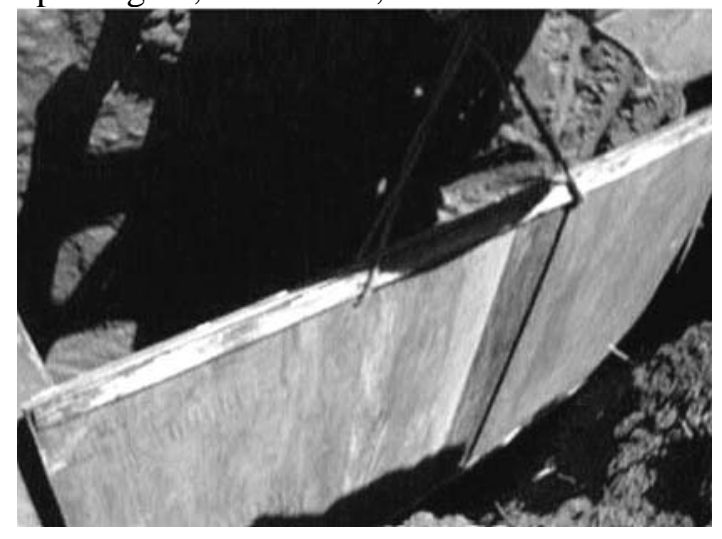

Figura 7 - Inserção de placa em madeira para redução da largura da barreira reativa

A composição final da mistura reativa (Figura 8) obedeceu à proporção de 6 toneladas de granalha para $16 \mathrm{~m}^{3}$ de areia. Assumindo a densidade da areia como sendo igual a $1,70 \mathrm{~g} / \mathrm{cm}^{3}$ (solo úmido), obtém-se 27,2 toneladas de areia, perfazendo a porcentagem final em peso da mistura de $81,9 \%$ de areia para $18,1 \%$ de granalha.

De acordo com ORTH; GILLHAM (1993), é recomendada mistura composta por $15 \%$ em peso de ferro para $85 \%$ de areia. Ainda, se for a densidade aproximada para areia seca, de $1,30 \mathrm{~g} / \mathrm{cm}^{3}$, refaz-se a porcentagem final em peso da mistura reativa para $77,6 \%$ de areia e $22,4 \%$ 
de granalha.

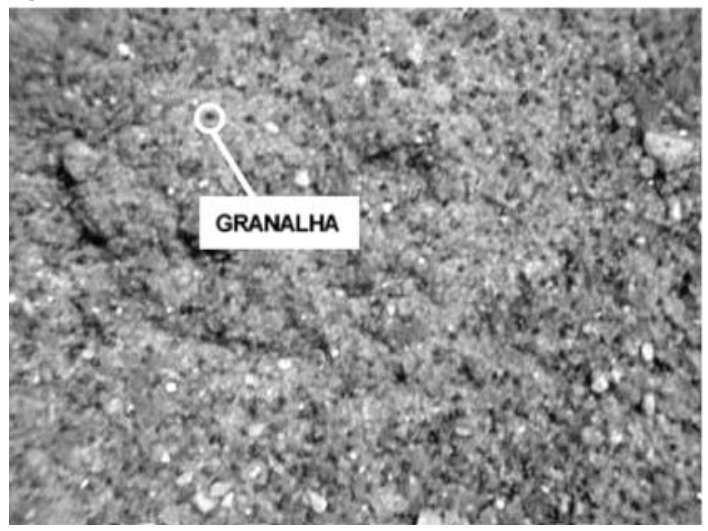

Figura 8 - Matriz reativa de areia e granalha

A mistura foi inserida na cava separada pela placa guia em madeira através de pá carregadeira modelo 930 (Figura 9). A ausência de água subterrânea migrante para o interior da trincheira e a estabilidade do solo escavado permitiu a inserção direta da mistura, sem necessidade de escoramento da vala.

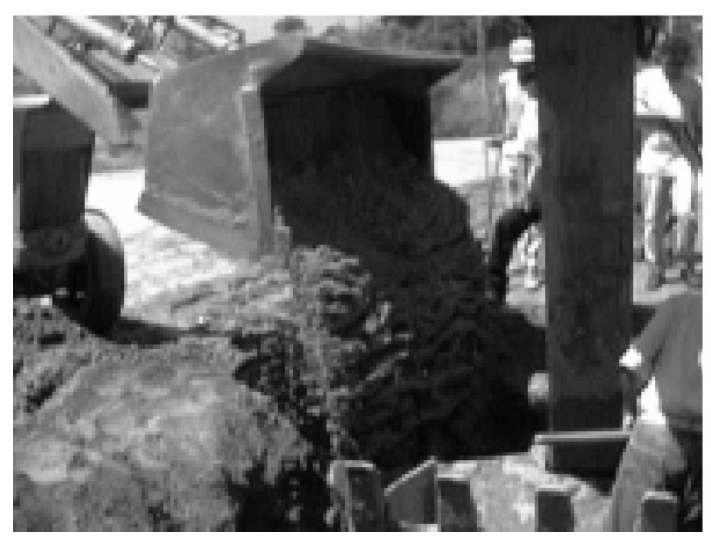

Figura 9 - Preenchimento da trincheira por mistura reativa

Os componentes, areia e granalha angulosa da IKK do Brasil, com diâmetros de 30 mesh, foram colocados em betoneira para homogeneização da mistura final. A distribuição por igual da mistura ao longo de toda a trincheira foi feita por funcionários (Figura 10) da empreiteira contratada pela Solventex, tendo sido mantida superfície superior plana da mistura para homogeneização sistema.

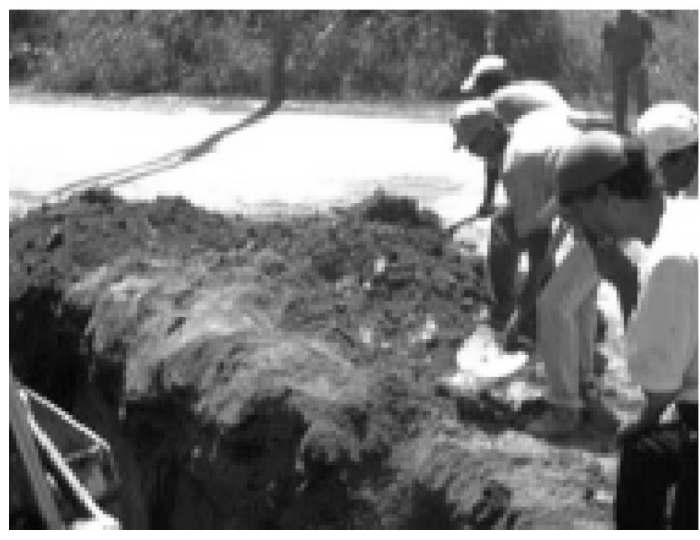

Figura 10 - Distribuição homogênea da mistura na vala

Ao fim do preenchimento da trincheira, a superfície do material reativo ficou nivelada a 1,0 m abaixo da superfície do terreno e a porção superior da trincheira foi preenchida por solo reposto.

Para monitoramento da eficiência da barreira reativa foram instalados inicialmente dois PMs, sendo um a montante, denominado PM SR01 M e instalado a cerca de 3,0 m de distância da face norte (orientação) da barreira reativa e outro a jusante, denominado PM SR02 J e distante cerca de $1,0 \mathrm{~m}$ da face sul da barreira.

O sistema de monitoramento foi completado em novembro de 1999, quando foram instalados os poços PM SR01 J e PM SR01 B, instalados a $5,0 \mathrm{~m}$ da parede sul da barreira reativa e no interior da barreira reativa, respectivamente.

Apesar do sistema de remediação ter sido monitorado desde o mês inicial de instalação, nem todos os parâmetros foram analisados desde os primeiros eventos.

A composição final dos dados, dos quais constam análises realizadas pelo laboratório CEIMIC Análises Ambientais S/C Ltda para determinação de compostos orgânicos voláteis (VOC - volatile organic compounds) pelo método EPA 8260 da USEPA (United States Environmental Protection Agency), análises realizadas pelo laboratório TCA - Empresa de Apoio Tecnológico, Consultoria Ambiental e Comércio Ltda. para determinação de parâmetros inorgânicos e medidas de parâmetros físico-químicos efetuadas em campo nas águas dos quatro poços de monitoramento (PM SR01 M, PM SR01 B, PM SR02 J e PM SR01 J), é disponível apenas para os eventos de monitoramento a partir de outubro de 2000, razão pela qual são apresentados neste trabalho apenas os doze últimos eventos de 
monitoramento (outubro de 2000 a setembro de 2001). Ainda assim, a partir do terceiro evento de monitoramento (os dois eventos iniciais foram efetuados em 11 de outubro de 2000 e 16 de novembro de 2000), houve uma modificação na lista de VOCs analisados, sendo eliminadas análises de acetona, 2-butanona, 2-hexanona e 4-metil-2-pentanona e substituídas as análises de 1,2-dicloroeteno por análises de trans-1,2-dicloroeteno e cis-1,2-dicloroeteno. A lista final de VOCs analisados para monitoramento do sistema apresenta clorometano, bromometano, cloreto de vinila, cloroetano, cloreto de metileno, disulfeto de carbono, 1,1-dicloroeteno, 1,1-dicloroetano, trans-1,2-dicloroeteno, cis-1,2-dicloroeteno, clorofórmio,

1,2-dicloroetano, 1,1,1-tricloroetano, tetracloreto de carbono, bromodiclorometano, 1,2-dicloropropano, trans-1,3-dicloropropeno, tricloroeteno, dibromoclorometano, 1,1,2-tricloroetano, benzeno, cis-1,3-dicloropropeno, bromofórmio, tetracloroeteno, 1,1,2,2-tetracloroetano, tolueno, clorobenzeno, etilbenzeno, xilenos e estireno.

\section{RESULTADOS E DISCUSSÃO}

Da lista de VOCs analisados, clorometano, bromometano, disulfeto de carbono, 1,1,1-tricloroetano, tetracloreto de carbono, bromodiclorometano, 1,2-dicloropropano, trans-1,3-dicloropropeno, dibromoclorometano, cis-1,3-dicloropropeno, bromofórmio, 2-hexanona e estireno não foram identificados em qualquer um dos eventos de monitoramento em concentrações acima dos limites de detecção utilizados pelo laboratório e por este motivo suas concentrações foram consideradas como nulas para efeito de interpretações.
Para averiguação da eficiência do processo de degradação ocasionado pela inserção da barreira reativa, os dados obtidos do poço PM SR01 J foram descartados. A razão do descarte pode ser justificada de maneira simplificada. A boca dos poços PM SR01 M e PM SR01 J encontram-se praticamente no mesmo nível topográfico, e distam aproximadamente 8,0m uma da outra. A máxima diferença determinada no monitoramento do nível da água (NA) nos dois poços foi obtida em 16 de agosto de 2001 (NA no PM SR01 M igual a $1,41 \mathrm{~m}$ a partir da boca do poço e igual a 0,94 a partir da boca do PM SR01 J) e confere, com base nos dados apresentados, um gradiente hidráulico máximo de 5,9\%.

$\mathrm{O}$ solo local possui porosidade efetiva (medida em laboratório) igual a 12\%, valor sugerido por FETTER (1988) como máximo para solos argilo-arenosos e condizente com o tipo de solo identificado no local, e condutividade hidráulica (medida em campo) variando entre $8,1 \times 10^{-4} \mathrm{~cm} / \mathrm{s}$ e $3,0 \times 10^{-6} \mathrm{~cm} / \mathrm{s}$, o que confere à água subterrânea a velocidade de fluxo entre $0,001 \mathrm{~m} /$ dia e $0,344 \mathrm{~m} /$ dia. Desta forma, a água subterrânea deve percorrer o percurso entre os poços PM SR01 M e PM SR01 J em um tempo mínimo de cerca de 23 dias e, portanto, amostras coletadas no mesmo evento de monitoramento dos poços extremos de montante e jusante não refletem as eventuais interações provocadas pelo sistema de remediação avaliado.

Desta forma, o sumário dos resultados analíticos obtidos ao longo dos 12 eventos de monitoramento é apresentado na tabela 2 e o sumário das medidas de parâmetros físico-químicos e de parâmetros inorgânicos é apresentado na tabela 3 . 
Tabela 2 - Resultados analíticos dos 12 eventos de monitoramento dos poços (concentrações em $\mu \mathrm{g} / \mathrm{L}$ )

\begin{tabular}{|c|c|c|c|c|c|c|c|c|c|c|c|c|}
\hline \multirow{2}{*}{$\begin{array}{l}\text { Compostos } \\
(\mu \mathrm{g} / \mathrm{L})\end{array}$} & \multicolumn{4}{|c|}{$11 / 10 / 2000$} & \multicolumn{4}{|c|}{$16 / 11 / 2000$} & \multicolumn{4}{|c|}{$14 / 12 / 2000$} \\
\hline & $\begin{array}{c}\text { PMSR } \\
01 \mathrm{M}\end{array}$ & $\begin{array}{c}\text { PMSR } \\
01 B\end{array}$ & $\begin{array}{c}\text { PMSR } \\
02 \mathrm{~J}\end{array}$ & $\begin{array}{c}\text { PMSR } \\
01 \mathrm{~J}\end{array}$ & $\begin{array}{c}\text { PMSR } \\
01 \mathrm{M}\end{array}$ & $\begin{array}{c}\text { PMSR } \\
\text { 01B }\end{array}$ & $\begin{array}{c}\text { PMSR } \\
02 \mathrm{~J}\end{array}$ & $\begin{array}{c}\text { PMSR } \\
01 \mathrm{~J}\end{array}$ & $\begin{array}{c}\text { PMSR } \\
01 \mathrm{M}\end{array}$ & $\begin{array}{c}\text { PMSR } \\
\text { 01B }\end{array}$ & $\begin{array}{c}\text { PMSR } \\
02 \mathrm{~J}\end{array}$ & $\begin{array}{c}\text { PMSR } \\
01 \mathrm{~J}\end{array}$ \\
\hline clorometano & 0 & 0 & 0 & 0 & 0 & 0 & 0 & 0 & 0 & 0 & 0 & 0 \\
\hline bromometano & 0 & 0 & 0 & 0 & 0 & 0 & 0 & 0 & 0 & 0 & 0 & 0 \\
\hline cloreto de vinila & 0 & 0 & 0 & 30 & 95 & 0 & 0 & 0 & 174 & 38 & 0 & 151 \\
\hline cloroetano & 0 & 2100 & 1100 & 32 & 168 & 1060 & 1040 & 10 & 307 & 3700 & 600 & 183 \\
\hline cloreto de metileno & 0 & 0 & 0 & 0 & 58 & 0 & 0 & 0 & 195 & 35 & 0 & 12 \\
\hline acetona & 180 & 0 & 0 & 0 & 722 & 0 & 0 & 0 & & & & \\
\hline disulfeto de carbono & 0 & 0 & 0 & 0 & 0 & 0 & 0 & 0 & 0 & 0 & 0 & 0 \\
\hline 1,1 dicloroeteno & 0 & 0 & 0 & 0 & 0 & 0 & 0 & 0 & 155 & 0 & 0 & 20 \\
\hline 1,1 dicloroetano & 32 & 0 & 0 & 376 & 90 & 0 & 0 & 81 & 525 & 400 & 0 & 3020 \\
\hline 1,2 dicloroeteno & 0 & 0 & 0 & 56 & 62 & 0 & 0 & 17 & & & & \\
\hline trans 1,2 dicloroeteno & & & & & & & & & 118 & 29 & 0 & 205 \\
\hline cis 1,2 dicloroeteno & & & & & & & & & 38 & 13 & 0 & 163 \\
\hline Clorofórmio & 0 & 0 & 0 & 0 & 0 & 0 & 0 & 0 & 0 & 0 & 0 & 138 \\
\hline 1,2 dicloroetano & 0 & 0 & 0 & 300 & 25 & 0 & 0 & 56 & 173 & 34 & 0 & 2340 \\
\hline 2 butanona & 0 & 0 & 1560 & 0 & 310 & 0 & 1320 & 0 & & & & \\
\hline 1,1,1 tricloroetano & 0 & 0 & 0 & 0 & 0 & 0 & 0 & 0 & 0 & 0 & 0 & 0 \\
\hline tetracloreto de carbono & 0 & 0 & 0 & 0 & 0 & 0 & 0 & 0 & 0 & 0 & 0 & 0 \\
\hline bromodiclorometano & 0 & 0 & 0 & 0 & 0 & 0 & 0 & 0 & 0 & 0 & 0 & 0 \\
\hline 1,2 dicloropropano & 0 & 0 & 0 & 0 & 0 & 0 & 0 & 0 & 0 & 0 & 0 & 0 \\
\hline trans 1,3 dicloropropeno & 0 & 0 & 0 & 0 & 0 & 0 & 0 & 0 & 0 & 0 & 0 & 0 \\
\hline tricloroeteno & 0 & 0 & 0 & 20 & 0 & 0 & 0 & 6 & 35 & 0 & 0 & 116 \\
\hline dibromoclorometano & 0 & 0 & 0 & 0 & 0 & 0 & 0 & 0 & 0 & 0 & 0 & 0 \\
\hline $1,1,2$ tricloroetano & 0 & 0 & 0 & 0 & 22 & 0 & 0 & 0 & 181 & 0 & 0 & 55 \\
\hline benzeno & 352 & 900 & 560 & 56 & 392 & 280 & 500 & 0 & 825 & 1450 & 390 & 420 \\
\hline cis 1,3 dicloropropeno & 0 & 0 & 0 & 0 & 0 & 0 & 0 & 0 & 0 & 0 & 0 & 0 \\
\hline bromofórmio & 0 & 0 & 0 & 0 & 0 & 0 & 0 & 0 & 0 & 0 & 0 & 0 \\
\hline 2 hexanona & 0 & 0 & 0 & 0 & 0 & 0 & 0 & 0 & & & & \\
\hline 4 metil 2 pentanona & 360 & 68000 & 120000 & 0 & 900 & 2740 & 47000 & 0 & & & & \\
\hline tetracloroeteno & 0 & 0 & 0 & 0 & 0 & 0 & 0 & 0 & 0 & 0 & 0 & 42 \\
\hline $1,1,2,2$ tetracloroetano & 0 & 0 & 0 & 0 & 0 & 0 & 0 & 0 & 0 & 0 & 0 & 0 \\
\hline tolueno & 2300 & 3400 & 3100 & 12 & 1570 & 920 & 5500 & 0 & 5450 & 1400 & 1600 & 105 \\
\hline clorobenzeno & 0 & 0 & 0 & 0 & 0 & 0 & 0 & 0 & 31 & 24 & 12 & 16 \\
\hline etilbenzeno & 150 & 3700 & 2700 & 24 & 128 & 1020 & 5500 & 0 & 325 & 1150 & 1950 & 199 \\
\hline xilenos & 472 & 9400 & 6300 & 26 & 432 & 2840 & 14250 & 0 & 1100 & 3100 & 4900 & 159 \\
\hline estireno & 0 & 0 & 0 & 0 & 0 & 0 & 0 & 0 & 0 & 0 & 0 & 0 \\
\hline \multirow{2}{*}{$\begin{array}{c}\text { Compostos } \\
(\mu \mathrm{g} / \mathrm{L})\end{array}$} & \multicolumn{4}{|c|}{$15 / 1 / 2001$} & & $12 / 2$ & 2001 & & & $12 / 3$ & 2001 & \\
\hline & $\begin{array}{c}\text { PMSR } \\
01 \mathrm{M}\end{array}$ & $\begin{array}{c}\text { PMSR } \\
01 B\end{array}$ & $\begin{array}{c}\text { PMSR } \\
\text { J }\end{array}$ & $\begin{array}{c}\text { PMSR } \\
01 \mathrm{~J}\end{array}$ & $\begin{array}{c}\text { PMSR } \\
01 \mathrm{M}\end{array}$ & $\begin{array}{c}\text { PMSR } \\
\text { 01B }\end{array}$ & $\begin{array}{c}\text { PMSR } \\
\text { 02J }\end{array}$ & $\begin{array}{c}\text { PMSR } \\
\text { 01J }\end{array}$ & $\begin{array}{c}\text { PMSR } \\
01 \mathrm{M}\end{array}$ & $\begin{array}{c}\text { PMSR } \\
\text { 01B }\end{array}$ & $\begin{array}{c}\text { PMSR } \\
\text { 02J }\end{array}$ & $\begin{array}{c}\text { PMSR } \\
01 \mathrm{~J}\end{array}$ \\
\hline clorometano & 0 & 0 & 0 & 0 & 0 & 0 & 0 & 0 & 0 & 0 & 0 & 0 \\
\hline bromometano & 0 & 0 & 0 & 0 & 0 & 0 & 0 & 0 & 0 & 0 & 0 & 0 \\
\hline cloreto de vinila & 104 & 108 & 0 & 35 & 6 & 142 & 0 & 0 & 108 & 109 & 0 & 97 \\
\hline cloroetano & 170 & 4580 & 650 & 73 & 10 & 7150 & 730 & 23 & 173 & 4525 & 470 & 204 \\
\hline $\begin{array}{l}\text { cloreto de metileno } \\
\text { acetona }\end{array}$ & 120 & 42 & 0 & 15 & 32 & 40 & 0 & 0 & 96 & 44 & 0 & 42 \\
\hline disulfeto de carbono & 0 & 0 & 0 & 0 & 0 & 0 & 0 & 0 & 0 & 0 & 0 & 0 \\
\hline 1,1 dicloroeteno & 62 & 0 & 0 & 10 & 0 & 6 & 0 & 0 & 18 & 0 & 0 & 26 \\
\hline 1,1 dicloroetano & 350 & 700 & 0 & 1080 & 42 & 825 & 0 & 92 & 365 & 650 & 0 & 2040 \\
\hline 1,2 dicloroeteno & & & & & & & & & & & & \\
\hline trans 1,2 dicloroeteno & 92 & 101 & 0 & 74 & 0 & 95 & 0 & 7 & 113 & 96 & 0 & 150 \\
\hline cis 1,2 dicloroeteno & 34 & 57 & 0 & 87 & 7 & 62 & 0 & 6 & 44 & 66 & 0 & 231 \\
\hline Clorofórmio & 11 & 10 & 0 & 111 & 0 & 11 & 0 & 8 & 0 & 10 & 0 & 346 \\
\hline 1,2 dicloroetano & 212 & 109 & 9 & 1000 & 60 & 103 & 7 & 63 & 147 & 123 & 0 & 2320 \\
\hline 2 butanona & & & & & & & & & & & & \\
\hline $1,1,1$ tricloroetano & 0 & 0 & 0 & 0 & 0 & 0 & 0 & 0 & 0 & 0 & 0 & 0 \\
\hline tetracloreto de carbono & 0 & 0 & 0 & 0 & 0 & 0 & 0 & 0 & 0 & 0 & 0 & 0 \\
\hline bromodiclorometano & 0 & 0 & 0 & 0 & 0 & 0 & 0 & 0 & 0 & 0 & 0 & 0 \\
\hline 1,2 dicloropropano & 0 & 0 & 0 & 0 & 0 & 0 & 0 & 0 & 0 & 0 & 0 & 0 \\
\hline trans 1,3 dicloropropeno & 0 & 0 & 0 & 0 & 0 & 0 & 0 & 0 & 0 & 0 & 0 & 0 \\
\hline tricloroeteno & 31 & 8 & 0 & 59 & 10 & 7 & 0 & 5 & 32 & 0 & 0 & 158 \\
\hline dibromoclorometano & 0 & 0 & 0 & 0 & 0 & 0 & 0 & 0 & 0 & 0 & 0 & 0 \\
\hline $1,1,2$ tricloroetano & 208 & 30 & 0 & 28 & 97 & 31 & 0 & 0 & 300 & 39 & 0 & 78 \\
\hline benzeno & 580 & 1950 & 490 & 107 & 29 & 103 & 410 & 0 & 624 & 1950 & 350 & 248 \\
\hline cis 1,3 dicloropropeno & 0 & 0 & 0 & 0 & 0 & 0 & 0 & 0 & 0 & 0 & 0 & 0 \\
\hline bromofórmio & 0 & 0 & 0 & 0 & 0 & 0 & 0 & 0 & 0 & 0 & 0 & 0 \\
\hline 2 hexanona & & & & & & & & & & & & \\
\hline 4 metil 2 pentanona & & & & & & & & & & & & \\
\hline tetracloroeteno & 0 & 0 & 0 & 28 & 0 & 0 & 0 & 0 & 0 & 0 & 0 & 69 \\
\hline 1,1,2,2 tetracloroetano & 0 & 0 & 0 & 0 & 0 & 0 & 0 & 0 & 0 & 0 & 0 & 0 \\
\hline tolueno & 3180 & 1500 & 1320 & 26 & 159 & 1500 & 910 & 0 & 3525 & 1350 & 1100 & 36 \\
\hline clorobenzeno & 23 & 42 & 13 & 0 & 0 & 38 & 14 & 0 & 26 & 50 & 15 & 0 \\
\hline etilbenzeno & 193 & 920 & 1840 & 34 & 8 & 780 & 1270 & 0 & 197 & 575 & 1700 & 0 \\
\hline xilenos & 609 & 2600 & 4640 & 56 & 28 & 2225 & 4090 & 0 & 728 & 1650 & 4700 & 165 \\
\hline estireno & 0 & 0 & 0 & 0 & 0 & 0 & 0 & 0 & 0 & 0 & 0 & 0 \\
\hline
\end{tabular}


Continuação

Tabela 2 - Resultados analíticos dos 12 eventos de monitoramento dos poços (concentrações em $\mu \mathrm{g} / \mathrm{L}$ )

\begin{tabular}{|c|c|c|c|c|c|c|c|c|c|c|c|c|}
\hline \multirow{2}{*}{$\begin{array}{c}\text { Compostos } \\
(\mu \mathrm{g} / \mathrm{L})\end{array}$} & \multicolumn{4}{|c|}{$17 / 4 / 2001$} & \multicolumn{4}{|c|}{$18 / 5 / 2001$} & \multicolumn{4}{|c|}{$18 / 6 / 2001$} \\
\hline & $\begin{array}{c}\text { PMSR } \\
01 \mathrm{M}\end{array}$ & $\begin{array}{c}\text { PMSR } \\
01 B\end{array}$ & $\begin{array}{c}\text { PMSR } \\
\text { 02J }\end{array}$ & $\begin{array}{c}\text { PMSR } \\
01 \mathrm{~J}\end{array}$ & $\begin{array}{c}\text { PMSR } \\
01 M\end{array}$ & $\begin{array}{c}\text { PMSR } \\
\text { 01B }\end{array}$ & $\begin{array}{l}\text { PMSR } \\
\text { 02J }\end{array}$ & $\begin{array}{c}\text { PMSR } \\
01 \mathrm{~J}\end{array}$ & $\begin{array}{c}\text { PMSR } \\
01 M\end{array}$ & $\begin{array}{c}\text { PMSR } \\
01 \mathrm{~B}\end{array}$ & $\begin{array}{c}\text { PMSR } \\
\text { 02J }\end{array}$ & $\begin{array}{c}\text { PMSR } \\
01 \mathrm{~J}\end{array}$ \\
\hline clorometano & 0 & 28 & 0 & 0 & 0 & 0 & 0 & 0 & 0 & 0 & 0 & 0 \\
\hline bromometano & 0 & 0 & 0 & 0 & 0 & 0 & 0 & 0 & 0 & 0 & 0 & 0 \\
\hline cloreto de vinila & 136 & 55 & 0 & 0 & 1500 & 138 & 0 & 134 & 6725 & 67 & 0 & 420 \\
\hline cloroetano & 20 & 3300 & 450 & 0 & 191 & 6300 & 1400 & 238 & 0 & 11125 & 2200 & 340 \\
\hline $\begin{array}{l}\text { cloreto de metileno } \\
\text { acetona }\end{array}$ & 0 & 32 & 0 & 0 & 577 & 468 & 1200 & 340 & 0 & 37 & 0 & 0 \\
\hline disulfeto de carbono & 0 & 0 & 0 & 0 & 0 & 0 & 0 & 0 & 0 & 0 & 0 & 0 \\
\hline 1,1 dicloroeteno & 0 & 0 & 0 & 0 & 147 & 0 & 0 & 0 & 0 & 0 & 0 & 28 \\
\hline 1,1 dicloroetano & 97 & 291 & 0 & 36 & 2700 & 1070 & 0 & 2000 & 4200 & 375 & 0 & 3660 \\
\hline $\begin{array}{l}1,2 \text { dicloroeteno } \\
\text { trans } 1,2 \text { dicloroeteno }\end{array}$ & \multicolumn{5}{|c|}{ 1,2 dicloroeteno } & 110 & 0 & 140 & 250 & 17 & 0 & 280 \\
\hline cis 1,2 dicloroeteno & 16 & 0 & 0 & 0 & 594 & 72 & 0 & 120 & 6 & 0 & 0 & 180 \\
\hline Clorofórmio & 0 & 0 & 0 & 0 & 187 & 0 & 0 & 150 & 101 & 0 & 0 & 260 \\
\hline $\begin{array}{l}1,2 \text { dicloroetano } \\
2 \text { butanona }\end{array}$ & 13 & 27 & 0 & 30 & 603 & 172 & 0 & 1700 & 0 & 0 & 0 & 3400 \\
\hline 1,1,1 tricloroetano & 0 & 0 & 0 & 0 & 0 & 0 & 0 & 0 & 0 & 0 & 0 & 0 \\
\hline tetracloreto de carbono & 0 & 0 & 0 & 0 & 0 & 0 & 0 & 0 & 0 & 0 & 0 & 0 \\
\hline bromodiclorometano & 0 & 0 & 0 & 0 & 0 & 0 & 0 & 0 & 0 & 0 & 0 & 0 \\
\hline 1,2 dicloropropano & 0 & 0 & 0 & 0 & 0 & 0 & 0 & 0 & 0 & 0 & 0 & 0 \\
\hline trans 1,3 dicloropropeno & 0 & 0 & 0 & 0 & 0 & 0 & 0 & 0 & 0 & 0 & 0 & 0 \\
\hline tricloroeteno & 0 & 0 & 0 & 0 & 118 & 0 & 0 & 100 & 0 & 0 & 0 & 187 \\
\hline dibromoclorometano & 0 & 0 & 0 & 0 & 0 & 0 & 0 & 0 & 0 & 0 & 0 & 0 \\
\hline 1,1,2 tricloroetano & 0 & 0 & 0 & 0 & 5500 & 42 & 0 & 54 & 5500 & 0 & 0 & 67 \\
\hline benzeno & 267 & 1225 & 252 & 0 & 1200 & 2200 & 900 & 320 & 1500 & 2075 & 850 & 500 \\
\hline cis 1,3 dicloropropeno & 0 & 0 & 0 & 0 & 0 & 0 & 0 & 0 & 0 & 0 & 0 & 0 \\
\hline bromofórmio & 0 & 0 & 0 & 0 & 0 & 0 & 0 & 0 & 0 & 0 & 0 & 0 \\
\hline 2 hexanona & & & & & & & & & & & & \\
\hline $\begin{array}{l}4 \text { metil } 2 \text { pentanona } \\
\text { tetracloroeteno }\end{array}$ & 0 & 0 & 0 & 0 & 0 & 0 & 0 & 56 & 0 & 0 & 0 & 73 \\
\hline $1,1,2,2$ tetracloroetano & 0 & 0 & 0 & 0 & 0 & 0 & 0 & 0 & 0 & 0 & 0 & 0 \\
\hline tolueno & 1800 & 1025 & 850 & 0 & 8700 & 2900 & 500 & 120 & 12575 & 2200 & 76 & 145 \\
\hline clorobenzeno & 13 & 28 & 11 & 0 & 45 & 55 & 0 & 0 & 69 & 37 & 30 & 24 \\
\hline etilbenzeno & 107 & 600 & 1550 & 0 & 398 & 520 & 800 & 180 & 575 & 550 & 700 & 300 \\
\hline xilenos & 339 & 1800 & 4650 & 10 & 1400 & 1600 & 2200 & 160 & 1900 & 1700 & 1950 & 200 \\
\hline \multirow[t]{2}{*}{ estireno } & 0 & 0 & 0 & 0 & 0 & 0 & 0 & 0 & 0 & 0 & 0 & 0 \\
\hline & \multicolumn{4}{|c|}{$24 / 7 / 2001$} & & $16 / 8$ & 2001 & & & $14 / 9$ & 2001 & \\
\hline Compostos & PMSR & PMSR & PMSR & PMSR & PMSR & PMSR & PMSR & PMSR & PMSR & PMSR & PMSR & PMSR \\
\hline$(\mu \mathrm{g} / \mathrm{L})$ & $01 \mathrm{M}$ & 01B & $02 \mathrm{~J}$ & $01 \mathrm{~J}$ & $01 \mathrm{M}$ & 01B & $02 \mathrm{~J}$ & $01 \mathrm{~J}$ & $01 \mathrm{M}$ & 01B & $02 \mathrm{~J}$ & $01 \mathrm{~J}$ \\
\hline clorometano & 0 & 0 & 0 & 0 & 0 & 0 & 0 & 0 & 0 & 0 & 0 & 0 \\
\hline bromometano & 0 & 0 & 0 & 0 & 0 & 0 & 0 & 0 & 0 & 0 & 0 & 0 \\
\hline cloreto de vinila & 3050 & 146 & 0 & 460 & 310 & 118 & 320 & 0 & 280 & 73 & 0 & 600 \\
\hline cloroetano & 380 & 8600 & 1950 & 420 & 100 & 6350 & 210 & 1170 & 1850 & 6350 & 74 & 240 \\
\hline $\begin{array}{l}\text { cloreto de metileno } \\
\text { acetona }\end{array}$ & 154 & 0 & 24 & 21 & 42 & 38 & 18 & 14 & 192 & 38 & 0 & 0 \\
\hline disulfeto de carbono & 0 & 7 & 0 & 0 & 0 & 0 & 0 & 0 & 0 & 0 & 0 & 0 \\
\hline 1,1 dicloroeteno & 6 & 4 & 0 & 36 & 0 & 4 & 40 & 0 & 0 & 0 & 0 & 51 \\
\hline 1,1 dicloroetano & 3500 & 824 & 4 & 3820 & 2500 & 650 & 3140 & 0 & 245 & 500 & 11 & 4540 \\
\hline 1,2 dicloroeteno & & & & & & & & & & & & \\
\hline trans 1,2 dicloroeteno & 147 & 75 & 0 & 312 & 69 & 81 & 317 & 0 & 23 & 48 & 0 & 400 \\
\hline cis 1,2 dicloroeteno & 13 & 34 & 0 & 294 & 16 & 32 & 309 & 0 & 0 & 0 & 0 & 380 \\
\hline Clorofórmio & 179 & 4 & 0 & 390 & 95 & 4 & 335 & 0 & 0 & 0 & 0 & 360 \\
\hline 1,2 dicloroetano & 990 & 82 & 0 & 3940 & 275 & 70 & 3180 & 0 & 31 & 0 & 7 & 4580 \\
\hline 2 butanona & & & & & & & & & & & & \\
\hline 1,1,1 tricloroetano & 0 & 0 & 0 & 0 & 0 & 0 & 0 & 0 & 0 & 0 & 0 & 0 \\
\hline tetracloreto de carbono & 0 & 0 & 0 & 0 & 0 & 0 & 0 & 0 & 0 & 0 & 0 & 0 \\
\hline bromodiclorometano & 0 & 0 & 0 & 0 & 0 & 0 & 0 & 0 & 0 & 0 & 0 & 0 \\
\hline 1,2 dicloropropano & 0 & 0 & 0 & 0 & 0 & 0 & 0 & 0 & 0 & 0 & 0 & 0 \\
\hline trans 1,3 dicloropropeno & 0 & 0 & 0 & 0 & 0 & 0 & 0 & 0 & 0 & 0 & 0 & 0 \\
\hline tricloroeteno & 12 & 3 & 0 & 158 & 20 & 0 & 178 & 0 & 0 & 0 & 0 & 224 \\
\hline dibromoclorometano & 0 & 0 & 0 & 0 & 0 & 0 & 0 & 0 & 0 & 0 & 0 & 0 \\
\hline $1,1,2$ tricloroetano & 2590 & 24 & 0 & 81 & 550 & 12 & 95 & 0 & 3 & 4 & 0 & 114 \\
\hline benzeno & 1558 & 2025 & 746 & 550 & 1500 & 2000 & 480 & 690 & 1650 & 2050 & 0 & 640 \\
\hline cis 1,3 dicloropropeno & 0 & 0 & 0 & 0 & 0 & 0 & 0 & 0 & 0 & 0 & 0 & 0 \\
\hline bromofórmio & 0 & 0 & 0 & 0 & 0 & 0 & 0 & 0 & 0 & 0 & 0 & 0 \\
\hline 2 hexanona & & & & & & & & & & & & \\
\hline 4 metil 2 pentanona & & & & & & & & & & & & \\
\hline tetracloroeteno & 4 & 0 & 0 & 96 & 6 & 0 & 116 & 0 & 0 & 0 & 0 & 137 \\
\hline $1,1,2,2$ tetracloroetano & 0 & 0 & 0 & 0 & 0 & 0 & 0 & 0 & 0 & 0 & 0 & 3 \\
\hline Tolueno & 13300 & 3062 & 109 & 181 & 12750 & 2700 & 159 & 203 & 13450 & 2250 & 24 & 237 \\
\hline clorobenzeno & 71 & 47 & 28 & 25 & 72 & 58 & 25 & 30 & 77 & 51 & 3 & 32 \\
\hline etilbenzeno & 618 & 450 & 570 & 316 & 600 & 400 & 229 & 490 & 700 & 350 & 90 & 320 \\
\hline Xilenos & 2125 & 1425 & 1450 & 190 & 1950 & 1200 & 173 & 1310 & 2050 & 1100 & 217 & 248 \\
\hline Estireno & 0 & 0 & 0 & 0 & 0 & 0 & 0 & 0 & 0 & 0 & 0 & 0 \\
\hline
\end{tabular}


Tabela 3 - Parâmetros físico-químicos e inorgânicos dos 12 eventos de monitoramento dos poços

\begin{tabular}{|c|c|c|c|c|c|c|c|c|c|c|c|c|}
\hline \multirow{2}{*}{$\begin{array}{l}\text { PARÂMETRO/ EVENTO } \\
\text { ferro }(\mathrm{mg} / \mathrm{L})\end{array}$} & \multicolumn{4}{|c|}{$16 / 10 / 2000$} & \multicolumn{4}{|c|}{$16 / 11 / 2000$} & \multicolumn{4}{|c|}{$14 / 12 / 2000$} \\
\hline & 16,2 & 16,4 & 3,4 & 2,82 & 0,58 & 18,2 & 6,29 & 1,54 & 0,58 & 85,2 & 2,44 & 23,4 \\
\hline ferro $2+(\mathrm{mg} / \mathrm{L})$ & 2,72 & 2,4 & 2,4 & 2,54 & 0,28 & 18 & 5,96 & 0,1 & 0,58 & 15,3 & 0,1 & 17,4 \\
\hline ferro 3+ (mg/L) & 13,5 & 14 & 1 & 0,28 & 0,3 & 0,2 & 0,33 & 1,44 & 0 & 69,9 & 2,34 & 6 \\
\hline $\mathrm{STD}(\mathrm{mg} / \mathrm{L})$ & 220 & 280 & 250 & 125 & 245 & 180 & 230 & 55 & 285 & 365 & 185 & 225 \\
\hline $\mathrm{pH}$ & 7,39 & 7,1 & 7,3 & 7,47 & 7,8 & 8,1 & 8,3 & 8,3 & 10,1 & 6,38 & 7,5 & 6,7 \\
\hline NA (m) & 0,99 & 0,72 & 0,61 & 0,94 & 0,81 & 0,6 & 0,6 & 1,17 & 1,08 & 0,63 & 0,63 & 1,02 \\
\hline Eh (mV) & 66 & 14 & 21 & 185 & -19 & -30 & -43 & 39 & 95 & 86 & 72 & 66 \\
\hline temperatura $\left({ }^{\circ} \mathrm{C}\right)$ & & & & & & & & & 23,5 & 23 & 24 & 22 \\
\hline PARÂMETRO/ EVENTO & \multicolumn{4}{|c|}{$15 / 1 / 2001$} & \multicolumn{4}{|c|}{$12 / 2 / 2001$} & \multicolumn{4}{|c|}{$12 / 3 / 2001$} \\
\hline ferro (mg/L) & 0,83 & 109 & 2,14 & 3,32 & 1,24 & 59,2 & 5,56 & 1,41 & 0,9 & 100 & 3,75 & 9,2 \\
\hline ferro $2+(\mathrm{mg} / \mathrm{L})$ & 0,3 & 98,3 & 1,7 & 2,88 & 0,67 & 5,96 & 4,75 & 0,76 & 0,62 & 25 & 2,97 & 0,98 \\
\hline ferro $3+(\mathrm{mg} / \mathrm{L})$ & 0,53 & 10,7 & 0,44 & 0,44 & 0,57 & 53,2 & 0,81 & 0,65 & 0,28 & 75 & 0,78 & 8,22 \\
\hline $\mathrm{STD}(\mathrm{mg} / \mathrm{L})$ & 200 & 420 & 185 & 175 & 220 & 435 & 145 & 155 & 255 & 435 & 175 & 200 \\
\hline $\mathrm{pH}$ & 9,1 & 7 & 7,35 & 7 & 7,35 & 6,14 & 6,62 & 6,59 & 7,23 & 6,5 & 6,94 & 6,6 \\
\hline NA (m) & 1,04 & 0,68 & 0,67 & 1,09 & 0,8 & 0,4 & 0,4 & 0,77 & 0,5 & 0,5 & 0,5 & 0,89 \\
\hline Eh $(\mathrm{mV})$ & 90 & 78 & 62 & 65 & 45 & 0,58 & 0,63 & 1,02 & 10,8 & 6,3 & 6,8 & 5,5 \\
\hline temperatura $\left({ }^{\circ} \mathrm{C}\right)$ & 27 & 26 & 26 & 25 & 27 & 27 & 27 & 27 & 25 & 24 & 24 & 23 \\
\hline PARÂMETRO/ EVENTO & \multicolumn{4}{|c|}{$17 / 4 / 2001$} & \multicolumn{4}{|c|}{$18 / 5 / 2001$} & \multicolumn{4}{|c|}{$18 / 6 / 2001$} \\
\hline ferro (mg/L) & 7,8 & 86,8 & 6,37 & 4,29 & 26 & 146 & 7,84 & 18,5 & 72 & 126 & 13,5 & 21,8 \\
\hline ferro $2+(\mathrm{mg} / \mathrm{L})$ & 2,39 & 1,76 & 2,33 & 1,92 & 23,8 & 138 & 7,23 & 18,1 & 70,9 & 115 & 11,7 & 20,3 \\
\hline ferro $3+(\mathrm{mg} / \mathrm{L})$ & 5,41 & 85,04 & 4,04 & 2,37 & 2,2 & 8 & 0,61 & 0,4 & 1,1 & 11 & 1,8 & 1,5 \\
\hline $\mathrm{STD}(\mathrm{mg} / \mathrm{L})$ & 220 & 340 & 140 & 105 & 404 & 484 & 285 & 225 & 458 & 505 & 310 & 258 \\
\hline $\mathrm{pH}$ & 8,2 & 6,85 & 7,69 & 7,61 & 6,8 & 6,24 & 6,56 & 6,44 & 6,5 & 6,2 & 6,6 & 6,6 \\
\hline NA (m) & 0,85 & 0,52 & 0,46 & 0,98 & 0,8 & 0,42 & 0,43 & 0,88 & 0,77 & 0,41 & 0,37 & 0,85 \\
\hline Eh $(\mathrm{mV})$ & -54 & 49 & 25 & 192 & -73 & 2 & -10 & -52 & -95 & -47 & -40 & -67 \\
\hline temperatura $\left({ }^{\circ} \mathrm{C}\right)$ & 24 & 23 & 23,5 & 23 & 21 & 21 & 21 & 21 & 21 & 21 & 21 & 21 \\
\hline PARÂMETRO/ EVENTO & \multicolumn{4}{|c|}{$24 / 7 / 2001$} & \multicolumn{4}{|c|}{$16 / 8 / 2001$} & \multicolumn{4}{|c|}{$19 / 9 / 2001$} \\
\hline ferro (mg/L) & 70 & 152 & 15,6 & 35 & 81,2 & 161 & 28,8 & 10,2 & 32,8 & 126 & 7,18 & 27,6 \\
\hline ferro $2+(\mathrm{mg} / \mathrm{L})$ & 68,4 & 139 & 10 & 25,4 & 77,9 & 154 & 23,4 & 8 & 31,2 & 121 & 6,89 & 26,9 \\
\hline ferro 3+ (mg/L) & 1,6 & 13 & 5,6 & 9,6 & 3,3 & 7 & 5,4 & 2,2 & 1,6 & 5 & 0,29 & 0,7 \\
\hline $\mathrm{STD}(\mathrm{mg} / \mathrm{L})$ & 570 & 390 & 230 & 180 & 520 & 575 & 240 & 265 & 420 & 568 & 265 & 240 \\
\hline $\mathrm{Ph}$ & 6,82 & 6,12 & 6,61 & 6,54 & 6,61 & 6,15 & 6,55 & 6,82 & 7 & 6,55 & 6,97 & 6,71 \\
\hline NA (m) & 1,3 & 0,89 & 0,88 & 1,13 & 1,41 & 0,94 & 1,3 & 0,94 & 1,45 & 0,8 & 0,79 & 1,2 \\
\hline Eh (mV) & 31 & 72 & 11 & 23 & -25 & 40 & 15 & -18 & 134 & 158 & 257 & 134 \\
\hline temperatura $\left({ }^{\circ} \mathrm{C}\right)$ & 19 & 18 & 19 & 19 & 20 & 19 & 21 & 20 & 21,5 & 21 & 21 & 21 \\
\hline
\end{tabular}

Ao longo do ano hidrológico em que foi realizado o monitoramento nos poços, a eficiência do sistema de remediação na degradação de compostos clorados com duplas ligações em suas fórmulas estruturais (etenos) pôde ser comprovada.

Entre os meses de outubro de 2000 e julho de 2001 a afirmação anterior é justificada por concentrações de tetracloroeteno, tricloroeteno, 1,1-dicloroteno, 1,2-dicloroeteno (soma das concentrações dos isômeros trans e cis) e cloreto de vinila freqüentemente identificadas nas amostras coletadas no poço de montante e nulas em todos as amostras do período coletadas no poço de jusante.

A seqüência dos resultados positivos é interrompida no evento de monitoramento de agosto de 2001, no qual as concentrações obtidas são anômalas e, para um mesmo contaminante, apresentam-se por vezes superiores no poço de jusante em relação ao poço de montante. Os resultados do evento seguinte de monitoramento (14 de setembro de 2001), no entanto, retoma a eficiência até então observada, o que permite inferir que os resultados do mês anterior foram originados a partir de erros de procedimento não descritos e possivelmente ocorridos no ato da amostragem ou no manuseio das amostras 
durante a etapa analítica. A hipótese de fluxo de água contaminada acima da zona reativa da barreira pode ser descartada pelo fato dos níveis d'água medidos em cada um dos poços de monitoramento encontraram-se, no mês de agosto, nas maiores profundidades em comparação às medidas nos demais eventos.

Os gráficos da Figura 11 ilustram a evolução das concentrações da seqüência de etenos ao longo dos eventos de monitoramento e em cada evento permite verificar as diferenças de concentrações entre os poços instalados no sentido de fluxo da pluma de contaminação através da barreira reativa. $\mathrm{O}$ gráfico referente ao primeiro evento de monitoramento, de 11 de outubro de 2000, não é apresentado, pois nesta data nenhum dos compostos de interesse superou os limites de detecção.

Como já discutido, as características originais da fonte de contaminação não permitem definir as concentrações originais e, portanto, inviabilizam o balanço de massa para verificação da eficiência da remediação. No entanto, os gráficos da Figura 11 indicam concentrações de cloreto de vinila presentes em todos os eventos de monitoramento no poço PM SR01 M e ausência deste contaminante nas amostras do poço PM SR02 J, com exceção do evento anômalo de agosto de 2001.

Não foram identificadas concentrações de tetracloreto de carbono acima dos limites de detecção, mas a seqüência de degradação redutiva pode ser inferida a partir do clorofórmio (PANKOW; CHERRY, 1996), que foi identificado em amostras coletadas no poço de montante e não foi identificado no poço de jusante, salvo no evento de monitoramento de agosto de 2001. O produto possível desta degradação, cloreto de metileno, obedeceu ao mesmo padrão de identificação, como pode ser observado no gráfico da figura 12 . O gráfico dos resultados analíticos referentes ao evento de monitoramento de outubro de 2000 não é apresentado na figura 12, pois não foram determinadas concentrações acima do limite de detecção. Apesar de inesperadas (a literatura não relata degradação abiótica destes compostos na presença de ferro zero-valente), reduções nas concentrações de 1,1-dicloroetano e 1,2-dicloroetano foram obtidas como padrão em todos os eventos de monitoramento, sendo reduzidas a valores inferiores aos limites de detecção dos métodos analíticos na maioria dos casos e determinadas em concentrações residuais (máxima de 9,0 $\mu \mathrm{g} / \mathrm{L}$ ) nos meses de janeiro, fevereiro, julho e setembro de 2001.

O processo de degradação dos compostos clorados constituídos apenas por ligações simples (etanos), no entanto, não ocorreu em tempo de residência suficiente para completa dehalogeneização, tendo sido obtidas concentrações elevadas de cloroetano no poço de jusante em todos os eventos de monitoramento, como ilustrado nos gráficos da figura 13. A variação das concentrações de cloroetano no sentido de fluxo da água subterrânea (do PM SR01 M ao PM SR02 J) denotam o processo de degradação imposto pela barreira reativa, uma vez que as concentrações deste composto invariavelmente são maiores nas amostras do poço PM SR01 B em comparação às amostras do PM SR01 M e menores quando comparadas às amostras do poço de jusante. 

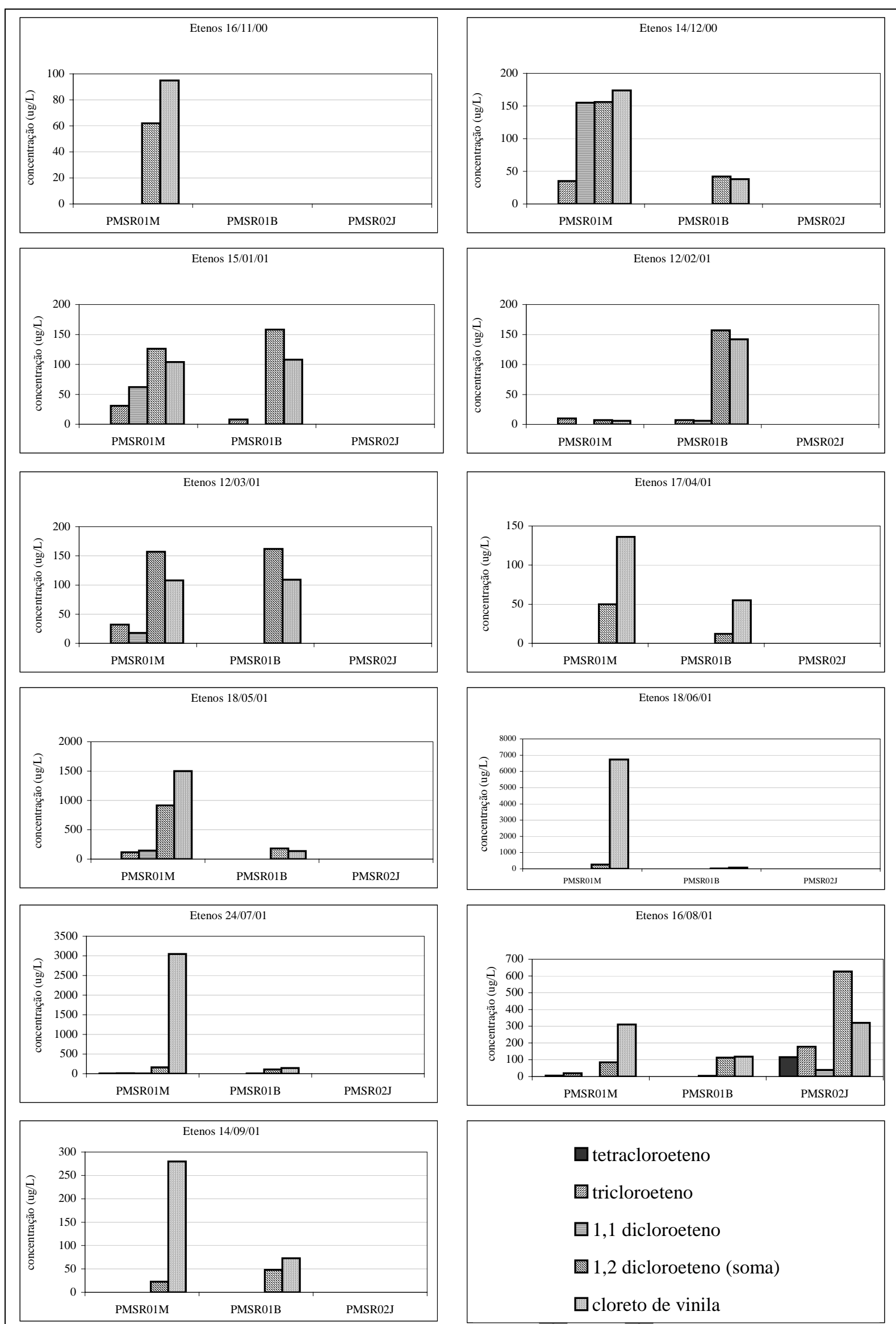

$\square$ tetracloroeteno

四 tricloroeteno

물 1,1 dicloroeteno

$\square$ 1,2 dicloroeteno (soma)

$\square$ cloreto de vinila

Figura 11 - Evolução das concentrações de etenos ao longo dos eventos de monitoramento 


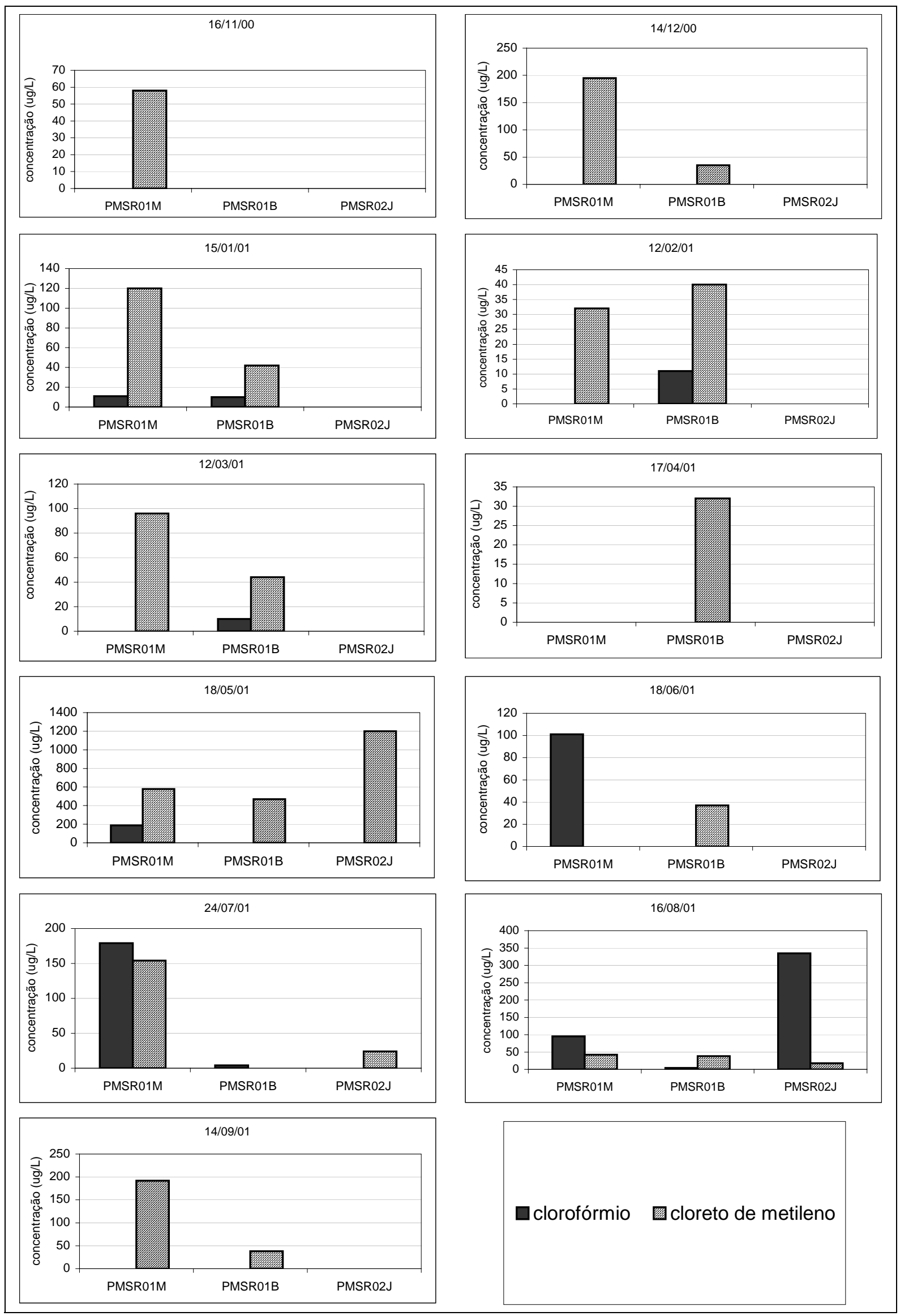

Figura 12 - Evolução das concentrações de clorofórmio e cloreto de metileno 


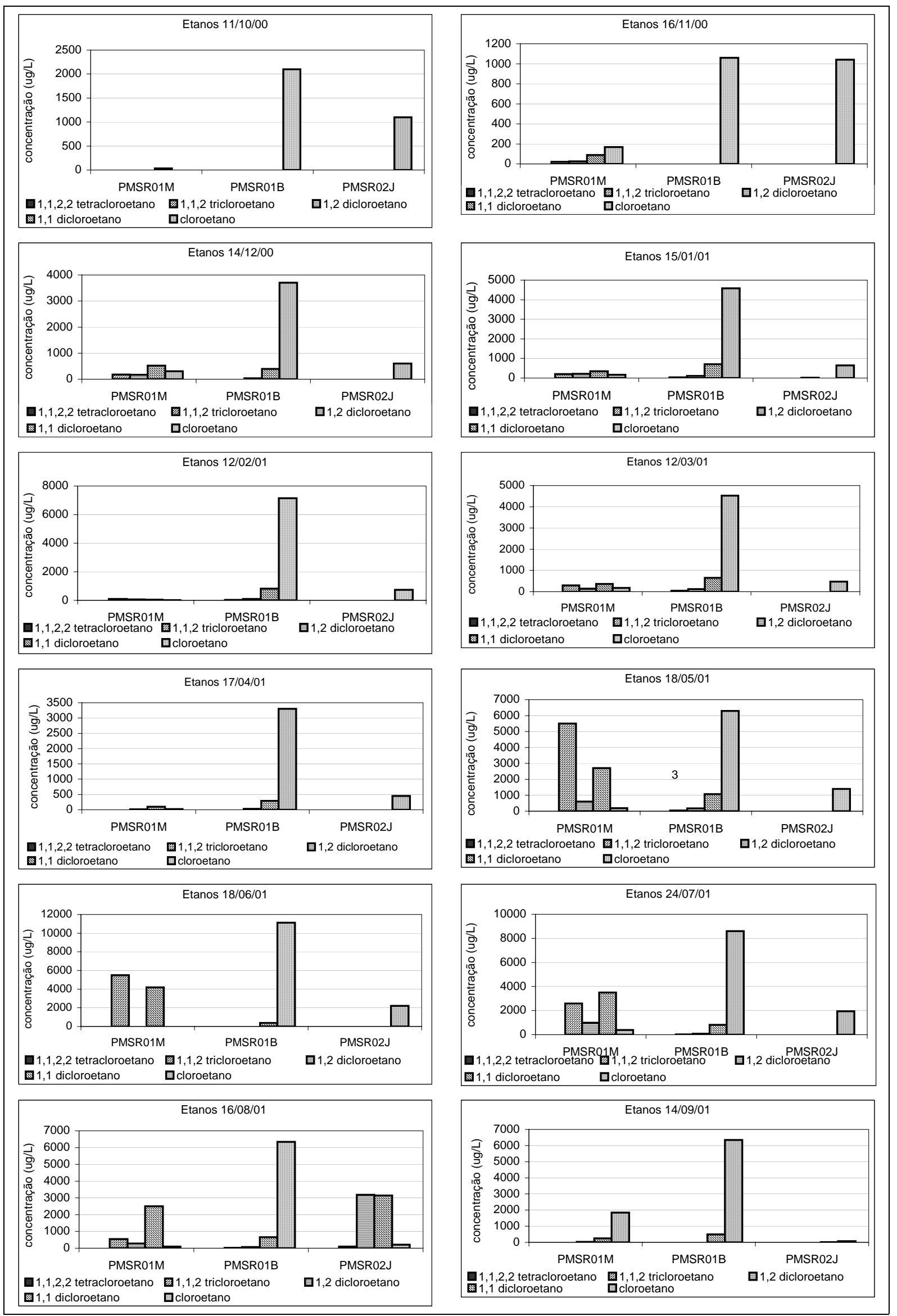

Figura 13 - Evolução das concentrações de etanos ao longo dos eventos de monitoramento 


\section{CONCLUSÕES}

A barreira reativa instalada em escala piloto a jusante da Solventex Indústria Química Ltda apresentou ao longo de 29 meses de monitoramento a eficiência esperada na dehalogeneização de etenos.

Mesmo na ausência de um balanço de massa definido, uma vez que não é conhecida a composição original da pluma de contaminação, as análises para determinação de VOC evidenciam que a barreira reativa preenchida por ferro zero-valente não é suficiente para remediação de todos os compostos (benzeno, por exemplo) determinados na área avaliada exigindo a adoção de técnicas mistas de remediação. Ainda assim, solventes clorados de cadeias simples (etanos) apresentaram degradação inesperada ao longo dos eventos de monitoramento, contudo com tempo de residência insuficiente para completa dehalogeneização, o que resultou em concentrações de cloroetano em amostra do poço de jusante.

Para avaliação da eficiência de sistemas de remediação por barreiras reativas, a simples avaliação das concentrações de VOC, como apresentada neste trabalho, fornece evidências suficientes para afirmar que o sistema monitorado apresentou total eficiência na degradação dos compostos clorados monitorados na área avaliada.

\section{RECOMENDAÇÕES}

Para obter eficiência em novos sistemas de remediação que sigam a metodologia apresentada neste trabalho, recomenda-se que a hidrogeologia local e a extensão da pluma de contaminantes sejam muito bem definidas, de forma que a barreira possa ser corretamente dimensionada para captação de toda a frente de contaminação e que suas dimensões sejam suficientes para total dehalogeneização dos compostos de interesse.

Para a avaliação da eficiência do sistema de remediação, o monitoramento das concentrações de VOCs é eficaz. A avaliação da longevidade da barreira é um outro enfoque de pesquisa e deve englobar análises de outros parâmetros que permitam definir efeitos geoquímicos e biológicos no processo de degradação e no material reativo.

\section{AGRADECIMENTOS}

À Solventex Indústria Química Ltda por ter acreditado no sistema de remediação e por ter cedido os dados para a elaboração deste trabalho. Ao Alexandre Olio, por toda a sua contribuição para o sucesso do projeto.

\section{REFERÊNCIAS}

CETESB - Companhia de Tecnologia de Saneamento Ambiental. Estabelecimento de Valores Orientadores para Solos e Água Subterrânea no Estado de São Paulo: 2001. Relatório Final. São Paulo, 246p.

FETTER, C.W. Applied Hydrogeology. Merril Publishing Company. $2^{\text {nd }}$ edition. 591p. 1988.

Gillham, R.W.; O'Hannesin, S.F. MetalCatalysed Abiotic Degradation of Halogenated Organic Compounds. IAH Conference "Modern Trends I Hidrogeology", Hamilton, Ontario Canada, may 10-13. 1992.
ORTH, W.S.; GILLHAM, R.W. Mass Balance of Degradation of Trichloroethylene in The Presence of Iron Fillings. Joint CSCE-ASCE National Conference on Environmental Engineering, Montreal, July 12-14. 1993.

PANKOW, J.F.; CHERRY, J.A. Dense Chlorinated Solvents and Other DNAPLs in Groundwater. Waterloo Press. 1996.

WILKIN, R.T.; PULS, R.W.; SEWELL, G.W. Long-Term Performance of Permeable Reactive Barriers Using Zero-Valent Iron: Geochemical and Microbiological Effects. Ground Water, vol. 41, nº4; 493-503. 2003. 